Exposure assessment should be integrated in studies on the prevention and management of occupational asthma

Author(s): Dick Heederik and Frits van Rooy

Source: Occupational and Environmental Medicine, Vol. 65, No. 3 (March 2008), pp. 149-150

Published by: BMJ

Stable URL: https://www.jstor.org/stable/25835176

Accessed: 17-07-2020 09:24 UTC

JSTOR is a not-for-profit service that helps scholars, researchers, and students discover, use, and build upon a wide range of content in a trusted digital archive. We use information technology and tools to increase productivity and facilitate new forms of scholarship. For more information about JSTOR, please contact support@jstor.org.

Your use of the JSTOR archive indicates your acceptance of the Terms \& Conditions of Use, available at https://about.jstor.org/terms

$B M T$ is collaborating with JSTOR to digitize, preserve and extend access to Occupational and Environmental Medicine 


\title{
Exposure assessment should be integrated in studies on the prevention and management of occupational asthma
}

\author{
Dick Heederik, ${ }^{1}$ Frits van Rooy ${ }^{1,2}$
}

\begin{abstract}
Evidence-based medicine (EBM) approaches have recently been applied to occupational asthma. ${ }^{12}$ The EBM document by Newman Taylor et al for occupational asthma evaluates, among other issues, the existence of exposureresponse relations for sensitisation and asthma. The cited references indeed provide evidence that exposure-response curves exist for certain high molecular weight allergens. The risk for allergenspecific sensitisation and asthma increases steeply with increasing allergen exposure, especially in atopics. ${ }^{3}$ More sensitised individuals express respiratory symptoms at higher exposure than at low exposure. ${ }^{4}$ The time to development of allergy is shorter at higher exposures than at lower exposure. $^{5}$
\end{abstract}

The question arises of what the implications of all these findings are with regard to primary prevention of allergic respiratory disease? Exposure-response relations suggest that lowering the exposure will reduce the burden of disease. Some direct evidence exists which illustrates that reduction of exposure leads to reduction of disease burden. Reduction of the exposure, by introducing powder-free gloves, led to a reduction in the number of sensitised and asthmatic workers. ${ }^{6}$ This conclusion is based on ecological evidence as well as longitudinal intervention studies. The effect of exposure reductions on sensitisation in more complex situations, with multiple determinants of exposure, is not as clearly established. Uncertainty exists as to whether the risk for developing enzyme-related sensitisation and asthma in the detergent industry has reduced, because incidence data for the

${ }^{1}$ Institute for Risk Assessment Sciences, Division of Environmental Epidemiology, University Utrecht, The Netherlands; ${ }^{2}$ Netherlands Expertise Centre for Occupational Respiratory Disorders, Utrecht, The Netherlands

Correspondence to: Dr D Heederik, Institute for Risk Assessment Sciences, Division of Environmental Epidemiology, University Utrecht, PO Box 80198, 3508 TD, The Netherlands; d.j.j.heederik@uu.nl appropriate population at risk have not been collected.' A reduction in the incidence of sensitisation has been suggested in laboratory animal workers with exposure to urinary allergens, on the basis of a pre-post intervention comparison within a retrospective cohort. The intervention consisted of the introduction of a code of practice, engineering controls and educational lectures. However, because the population at risk was defined inappropriately in the calculation of annual incidence and migration out of the workforce seemed high, especially in more recent years, the presented incidence figures might underestimate the true incidence. In addition, changes in allergen level were not monitored which also limits the interpretation. ${ }^{8}$

Second, with regard to progression of disease, different opinions seem to exist. Continuation of exposure is associated with progression of symptoms. ${ }^{9}$ Specific work-related sensitised workers with high exposure have more symptoms than those with low exposure. ${ }^{5}{ }^{10}$ This suggests also that even in sensitised workers the presence and severity of symptoms is exposure-related. Similarly, exposure reduction may influence the presence and severity of symptoms in sensitised workers. Vandenplas et al compared results from studies involving complete elimination (174 individuals) or exposure reduction (102 individuals) from six studies and concluded that the likelihood of improvement or resolution of symptoms or of preventing deterioration is greater in workers who have no further exposure to the causative agent. ${ }^{11}$ In contrast, Beach et al conclude, on the basis of a detailed and structured EBM evaluation involving the same evidence, that "the evidence regarding outcomes for workers who reduce, rather than cease, their exposure is insufficient to draw firm conclusions". ${ }^{2}$ Why is the available evidence considered insufficient and what are some of the problems with most available intervention studies?
- A closer inspection of the literature on exposure cessation versus reduction, shows that among other methodological shortcomings, objective information on the intervention variable (exposure) is either not documented or in most cases based on subjective judgment only. Quantitative information is usually not collected. We know from the literature that exposure reductions are difficult to evaluate using subjective approaches and bias is a major complicating factor. ${ }^{12}$ Thus if and to what extent the exposure was truly reduced is not known and this potentially affects the internal validity; changes in outcome may not be related to changes in exposure only. Thus we cannot be certain if a reduction actually took place, and if it was relevant and sufficient enough to reduce symptoms or signs such as bronchial hyper-responsiveness or inflammation.

- Even if we conclude that some of these interventions were effective, external validity is still an issue. We cannot compare results across studies because we cannot compare exposure levels and exposure changes across studies.

Thus, at best there is uncertainty whether exposure cessation is the only reasonable option to manage sensitiserinduced occupational asthma. The scientific basis on the effect of exposure reduction strategies is limited and the quality of the exposure assessment component does not allow firm conclusions.

Most intervention studies involving respiratory allergy can best be characterised as "complex intervention studies". ${ }^{13}$ Complex interventions consist of several intervention components. Evaluation is known to be difficult because of problems with developing, identifying, documenting and reproducing the intervention. Such interventions closely resemble occupational healthcare practice, where several components can be identified to control exposure because several determinants of exposure exist (tasks, technologies, personal protective equipment, etc). These circumstances make it even more necessary to monitor the effect of interventions by following changes in exposure.

These observations have several implications

- There is a need for well-designed intervention studies among individuals with occupational asthma aimed at establishing the effect of 
gradual exposure reductions. Exposure reduction is worthy of discussion because it is an alternative to abrupt unemployment and loss of quality of life and income. However, such studies also involve ethical issues, which need to be explored further and balanced against the potential advantages. When undertaken, sound quantitative exposure assessment methodology needs application in intervention studies in order to assess intervention effects objectively.

- The past decade has seen the emergence of core concepts, usually described as "evidence-based medicine". These are used to evaluate the available scientific literature to obtain general conclusions and generate recommendations to be used in professional standards and future research agendas. It has been recognised that different study topics in EBM require different evaluation tools that go beyond the evaluation of quality of the classical randomised controlled trial or other epidemiological designs. ${ }^{14}$ Thus specific "evidencebased" tools need to be developed for the evaluation of the exposure assessment components of occupational studies, possibly even specific for exposure assessment for asthma. The tools should give an assessment of the quality of the exposure assessment component of a study with focus on potential biases which affect the exposure proxy or the resulting exposure response relation. If we do not succeed in developing such tools we will make incorrect inferences based on clinical, epidemiological and hygiene literature.

It is probably needless to say that asthma research benefited considerably from recent developments in the field of exposure assessment. Good exposure assessment practices will also in the future contribute to our understanding of the prevention and management of occupational allergy and asthma.

Competing interests: None declared.

Occup Environ Med 2008:65:149-150. doi:10.1136/oem.2005.024711

\section{REFERENCES}

1. Newman Taylor AJ, Nicholson PJ. Guidelines for the prevention, identification and management of occupational asthma: evidence review and recommendations. BOHRF, London, 2004.

2. Beach J, Rowe BH, Blitz S, et al. Diagnosis and management of occupational asthma. Evid Rep Technol Assess 127 2005:129:1-8.

3. Heederik D, Venables K, Malmberg $P$, et al. Exposure-response relationships for occupational respiratory sensitizers: results from an European study in laboratory animal workers. J Allergy Clin Immunol 1999; 103:678-84.

4. Nieuwenhuijsen MJ, Putcha V, Gordon S, et al. Exposure-response relations among laboratory animal workers exposed to rats. Occup Environ Med 2003;60:104-8.

5. Kruize H, Post W, Heederik D, et al. Respiratory allergy in laboratory animal workers: a retrospective cohort study using pre-employment screening data. Occup Environ Med 1997;11:830-5.

6. LaMontagne AD, Radi S, Elder DS, et al. Primary prevention of latex related sensitisation and occupational asthma: a systematic review. Occup Environ Med 2006;63:359-64.

7. Cullinan P, Tarlo S, Nemery B. The prevention of occupational asthma. Eur Respir J 2003:22:853-60.

8. Botham PA, Davies GE, Teasdale EL. Allergy to laboratory animals: a prospective study of its incidence and of the influence of atopy on its development. Occup Environ Med 1987:44:627-32.

9. Elliott L, Heederik D, Marshall S, et al. Progression of self-reported symptoms in laboratory animal allergy. J Allergy Clin Immunol 2005;116:127-32.

10. Houba R, Heederik D, Doekes G. Wheat sensitization and work related symptoms in the baking industry are preventable: an epidemiological study. Am J Respir Crit Care Med 1998;158:1499-503.

11. Vandenplas 0, Toren K, Blanc PD. Health and socioeconomic impact of work-related asthma. Eur Respir J 2003;22:689-97.

12. Kromhout H, Oostendorp Y, Heederik D, et al. Agreement between qualitative exposure estimates and quantitative exposure measurements. $A m \mathrm{~J}$ Ind Med 1987;12:551-62.

13. Campbell M, Fitzpatrick R, Haines A, et al. Framework for design and evaluation of complex interventions to improve health. BMJ 2000;321:694-6.

14. Glasziou P, Vandenbroucke J, Chalmers I. Assessing the quality of research. BMJ 2004;328:39-41. 